\title{
Top-seeded solution growth of $\mathrm{SrTiO}_{3}$ crystals and phase diagram studies in the $\mathrm{SrO}-\mathrm{TiO}_{2}$ system
}

\author{
Christo Guguschev, ${ }^{*}$ Detlef Klimm, Frank Langhans, Zbigniew Galazka, Dirk Kok, Uta Juda, and \\ Reinhard Uecker
}

\author{
Received 8th October 2013, Accepted Xth XXXXXXXXX 20XX \\ First published on the web $X t h X X X X X X X X X X 200 X$ \\ DOI: 10.1039/b000000x
}

The $\mathrm{TiO}_{2}$ rich part of the $(1-x) \mathrm{SrO}+x \mathrm{TiO}_{2}$ phase diagram $0.5 \leq x \leq 1.0$ was redetermined and the eutectic point between $\mathrm{SrTiO}_{3}$ and $\mathrm{TiO}_{2}$ was found at $x_{\text {eut }}=0.7700 \pm 0.0001 ; T_{\text {eut }}=(1449 \pm 3)^{\circ} \mathrm{C}$. From $\mathrm{TiO}_{2}$ rich melt solutions, $x=0.75$ centimeter'sized single crystals could be grown. The best crystals with etch pit density $<2 \times 10^{4} / \mathrm{cm}^{2}$ were obtained for growth directions $\langle 110\rangle$ and $\langle 100\rangle$. AFM investigation of the interface reveals layer-by-layer growth.

\section{Introduction}

Tausonite $\left(\mathrm{SrTiO}_{3}, \mathrm{STO}\right)$ is a cubic perovskite and high quality single crystalline bulk crystals are attractive as substrates for oxide heterostructures. Two dimensional electron gases have been found at the interface between $\mathrm{SrTiO}_{3}$ and the following oxides: $\mathrm{LaTiO}_{3}$ [15], $\mathrm{LaAlO}_{3}$ [14], $\mathrm{LaVO}_{3}$ [5], $\mathrm{LaGaO}_{3}[16], \mathrm{GdTiO}_{3}[11]$, and $\mathrm{KTaO}_{3}[8]$. It also has been found in $\mathrm{SrTiO}_{3} / \mathrm{SrTi}_{0.8} \mathrm{Nb}_{0.2} \mathrm{O}_{3}$ superlattices [6].

The observation of the conducting interfaces has led to an increasing demand of high quality single crystals for funda'mental research and devices having extraordinary properties and functionality. Most tausonite substrates which are used nowadays are grown by flame fusion growth with high dislo'cation densities $\left(>1 \times 10^{6} / \mathrm{cm}^{2}\right)$. These Verneuil-grown crystals are produced at industrial scale and they are commercially available. When it comes to higher structural perfection only a few crystal growth methods are suitable to reach the high quality demands with a sufficient crystal size. One of the methods is optical floating zone which yields crystals with dislocation densities typically between $(1-5) \times 10^{5} / \mathrm{cm}^{2} \quad$ [12]. With a cold crucible Czochralski technique (cold crucible pulling technique) [1] etch pit densities of $10^{2}-10^{5} / \mathrm{cm}^{2}$ can be reached. $\mathrm{SrTiO}_{3}$ with the lowest dislocation density can be grown from the flux $\left(0-10^{2} / \mathrm{cm}^{2}\right)[19,21]$.

$\mathrm{SrTiO}_{3}$ and $\mathrm{TiO}_{2}$ are setting up a eutectic subsystem where top-seeded solution growth (TSSG) can be used for the growth of $\mathrm{SrTiO}_{3}$ crystals at substantially lower temperature, compared to the growth from stoichiometric melts. However, there is a lack of thermodynamic data at this composition range in the literature. This work highlights the self-flux growth of

Leibniz Institute for Crystal Growth, Max-Born-Str. 2, D-12489 Berlin, Germany. E-mail: christo.guguschev@ikz-berlin.de; Fax: +49-30-63923003; Tel.: +49-30-6392-3124
$\mathrm{SrTiO}_{3}$ single crystals in a cylindrical shape, the refinement of the $\mathrm{SrO}-\mathrm{TiO}_{2}$ phase diagram, which now includes the thermodynamic data of the melt, by means of DTA/DSC measurements and a description of typical growth surface morphologies when using different seed orientations by the AFM method.

\section{Experimental}

Thermal analysis of commercial $\mathrm{SrTiO}_{3}$ crystals (CrysTec $\mathrm{GmbH}$, Berlin) was performed up to the melting point beyond $2000^{\circ} \mathrm{C}$ in a NETZSCH STA 429 calorimeter. Lidded tungsten crucibles in $99.9999 \%$ pure static He atmosphere and $\mathrm{W}-\mathrm{W} / \mathrm{Re}$ thermocouples were used. The significant aging of these thermocouples that is shown under given conditions was accounted for by a subsequent calibration run with $\mathrm{Al}_{2} \mathrm{O}_{3}$ powder, where melting point $T_{\mathrm{f}}$ and heat of fusion $\Delta H_{\mathrm{f}}$ are known (Fig. 11).

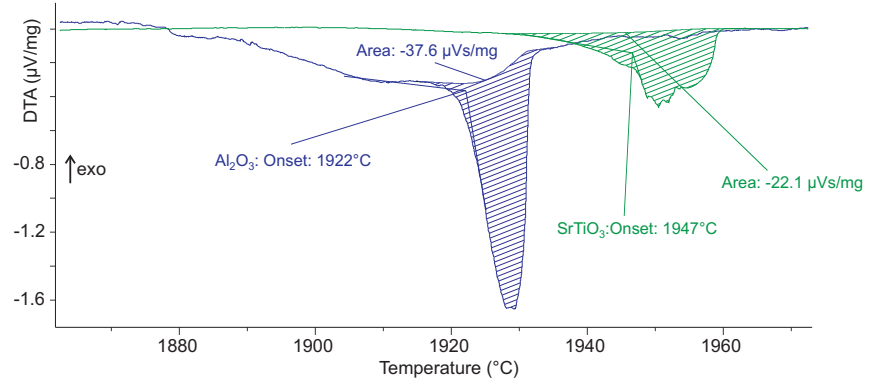

Fig. 1 DTA heating curves of $80.99 \mathrm{mg}$ crystalline $\mathrm{SrTiO}_{3}$ and $\mathrm{Al}_{2} \mathrm{O}_{3}$ powder standard. The latter melts at $2054^{\circ} \mathrm{C}$ with $\Delta H_{\mathrm{f}}=1161 \mathrm{~J} / \mathrm{g}$ [24].

In addition, 23 different $(1-x) \mathrm{SrO}+x \mathrm{TiO}_{2}$ powder mix- 
tures with $0.4014 \leq x \leq 0.9284$ were measured by DTA in a NETZSCH STA 449 calorimeter in flowing oxygen with platinum crucibles. According to the literature (Figs. 297, 298, 2334 in Ref. [3]) a eutectic point of $\mathrm{SrTiO}_{3} / \mathrm{TiO}_{2}$ should be near $x=0.8 ; 1440{ }^{\circ} \mathrm{C}$. It was the aim of these measurements to determine this eutectic point, and if possible also the liquidus points close to it, with high accuracy. Such high accuracy can be obtained only with the STA 449 due to lower temperatures. Moreover, the oxygen atmosphere was expected to suppress evaporation especially of strontium.

A solution composition of $75 \mathrm{~mol}_{\%} \mathrm{TiO}_{2}$ and $25 \mathrm{~mol} \% \mathrm{SrO}$ was used for the self-flux growth experiments. For these experiments, the dried, mixed and pressed starting powders of $\mathrm{SrCO}_{3}$ and $\mathrm{TiO}_{2}$ with purities of $99.99 \%$, were heated in platinum crucibles in $\mathrm{MoSi}_{2}$ muffle furnaces at maximum temperatures of $1620^{\circ} \mathrm{C}$.

Crystal growth was performed in a conventional $r f$-heated Czochralski setup (Cyberstar) with automatic diameter control. Verneuil-grown $\mathrm{SrTiO}_{3}$ single-crystals seeds (supplied by Crystec $\mathrm{GmbH}$, Berlin) with orientations of $\langle 100\rangle,\langle 110\rangle$ and $\langle 111\rangle$ were used. The growth runs were carried out in air with use of a platinum crucible embedded in $\mathrm{ZrO}_{2}$ and $\mathrm{Al}_{2} \mathrm{O}_{3}$ insulation. Most of the growth runs were performed using a pulling rate of $0.2 \mathrm{~mm} / \mathrm{h}$ and with an additional actively heated Pt after heater on top of the crucible. Different growth conditions were tested, which are shown in table 1. The surface temperature of the melt solution at the beginning of the growth was kept around $1540^{\circ} \mathrm{C}$, which was measured with a two colour pyrometer. This measured value is close to the calculated $T_{\text {liq }}=1535^{\circ} \mathrm{C}$ (Fig.7).

For EPD measurements samples of the grown crystals were oriented in the $\langle 100\rangle$ direction, chemo-mechanically polished and etched for several minutes in a mixture of $1 \mathrm{HF}$ $2 \mathrm{HNO}_{3}-2 \mathrm{H}_{2} \mathrm{O}$ [17]. A MFD-3D Stand Alone AFM (Atomic Force Microscope) from Asylum Research with an AEK 2002 acoustic isolation enclosure was used to investigate facets which were present at the growth interface. The measurements were done in contact mode in air and at room temperature using standard cantilevers from $\mu$ mash (silicon, tip diameter $<10 \mathrm{~nm}$, spring constant $2.8 \mathrm{~N} / \mathrm{m}$ ). The scan size varied between $5 \times 5 \mu \mathrm{m}^{2}$ and $10 \times 10 \mu \mathrm{m}^{2}$.

\section{Results and discussion}

\subsection{Crystal growth and characterization}

By using an inductively heated Czochralski setup cylindrical $\mathrm{SrTiO}_{3}$ single crystals could be obtained. In Fig. 2a a single crystal is shown, which was pulled in the $\langle 100\rangle$ direction. Even by using Verneuil-grown seeds, high quality tausonite crystals with a representative EPD value of $1.7 \times 10^{4} / \mathrm{cm}^{2}$ have been grown. The convex growth interface left in Fig. 2 a shows a (100) facet at its center. At the cylindrical part of the crystal, $\{110\}$ facets, which grow slowest, are present. Mainly the non-faceted faces are covered by rutile $\left(\mathrm{TiO}_{2}\right)$ and tausonite crystals grown from the vapour phase. To minimize the condensation of rutile on the surface of single crystals, the application of an after heater is necessary which keeps the oversaturation of titanium oxide in the vapour as low as possible.
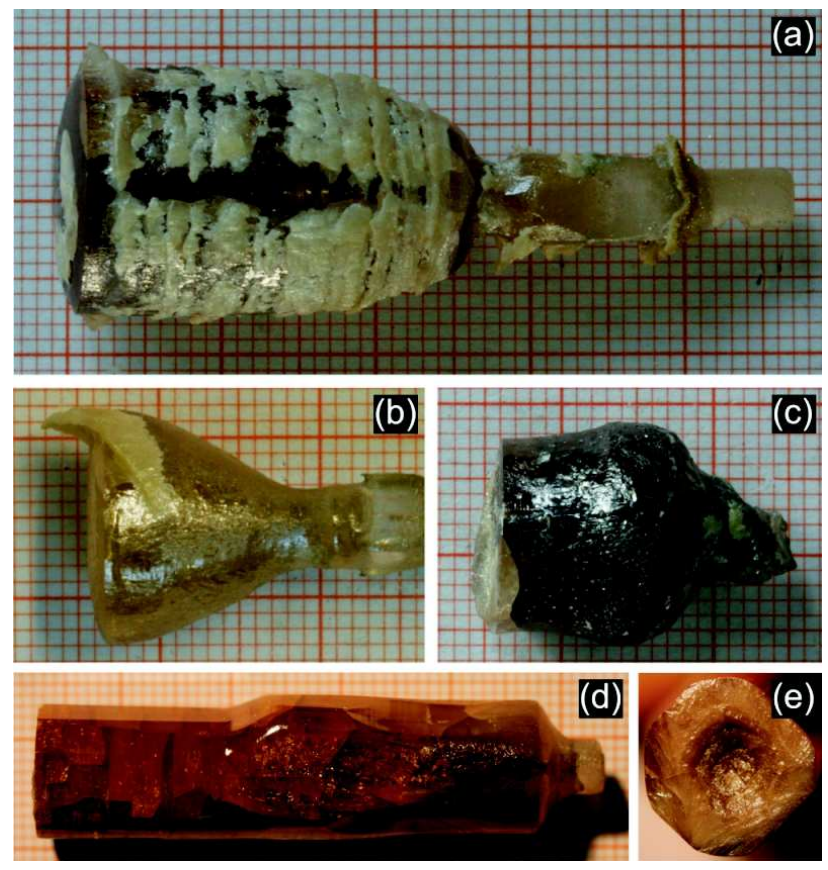

Fig. $2 \mathrm{SrTiO}_{3}$ crystals grown by self flux method with convex (a), W-shaped (b), nearly flat (c) and pronounced concave growth interfaces (d,e). Pulling directions of the crystals (a-d) were $\langle 100\rangle$, $\langle 110\rangle,\langle 111\rangle$ and $\langle 100\rangle$, respectively and the growth conditions (see table 11 were T1, T3, T4, T2, respectively. Interfaces are partially covered by the frozen melt solution (a-e) and by crystals grown from the vapor phase (a). A pulling rate of $0.2 \mathrm{~mm} / \mathrm{h}$ was used for the crystals shown in a-c and mainly $0.35 \mathrm{~mm} / \mathrm{h}$ was used for the crystal shown in $\mathrm{d}$ and $\mathrm{e}$.

Growth interfaces between nearly flat (Fig. 2k), w-shaped (Fig. 2b) and concave (Fig. 2ab-e) were observed, depending on the growth conditions (table 1) and orientation of the crystals. Non-convex interfaces, especially strong pronounced concave growth interfaces (Fig. 22) lead to a formation of cavities in the central region of the crystal, where the melt can penetrate into the crystals core, causing the crystal to crack upon cooling, which can be seen in Fig. 2 d. The outer parts of the crystal retain the high crystal quality (EPD $1.5 \times 10^{4} / \mathrm{cm}^{2}$ ), which is similar to the crystals pulled in $\langle 100\rangle$ direction without use of an additional after heater. The cracking can be explained by the deviations of thermal expansion properties of the two solid phases, tausonite and rutile, which crystallize 
Table 1 Crystal growth conditions

\begin{tabular}{cccccc}
\hline $\begin{array}{c}\text { growth } \\
\text { condition }\end{array}$ & $\begin{array}{c}\text { afterheater } \\
\text { in use }\end{array}$ & $\begin{array}{c}\text { axial } \\
\text { gradient }\end{array}$ & $\begin{array}{c}\text { pulling rate } \\
(\mathrm{mm} / \mathrm{h})\end{array}$ & $\begin{array}{c}\text { seed } \\
\text { orientation }\end{array}$ & $\begin{array}{c}\text { rotation rate } \\
(\mathrm{rpm})\end{array}$ \\
\hline T1 & no & very high & 0.2 & $\langle 100\rangle$ & 20 \\
T2 & yes & very low & $0.2-0.6$ & $\langle 100\rangle$ & 20 \\
T3 & yes & moderate & 0.2 & $\langle 110\rangle$ & 5 \\
T4 & yes & moderate & 0.2 & $\langle 111\rangle$ & 5 \\
\hline
\end{tabular}

simultaneously from the melt upon reaching the eutectic temperature. The difference of the thermal expansion coefficient is more than one order of magnitude [4, 9]. Moreover, a concave interface leads to a higher density of grown-in dislocations which also may cause cracking. Appropriate growth and post-growth conditions have to be applied for different pulling directions to yield convex growth interfaces, prevent condensation of rutile at crystal surfaces and reduce the amount of frozen melt solution at the bottom of the crystal at the same time.

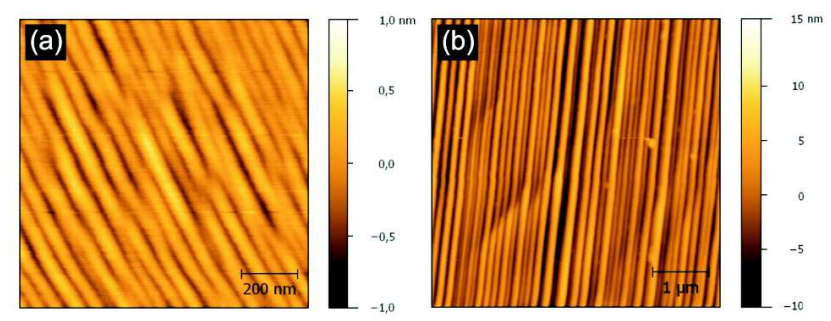

Fig. 3 AFM measurements of the as-grown facets at the central part of the melt-solid interfaces for different pulling directions. (a) $\langle 100\rangle$ and (b) $\langle 110\rangle$ direction.
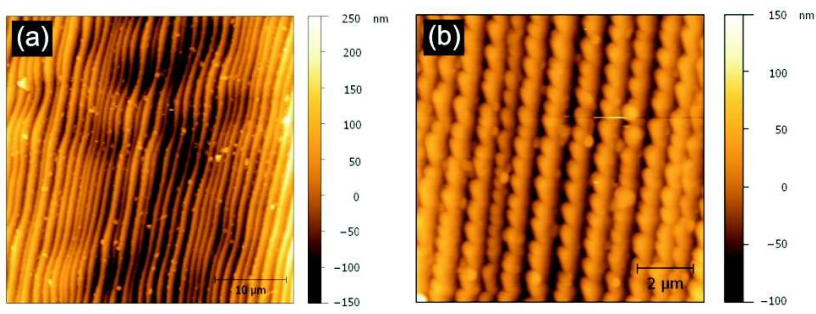

Fig. 4 AFM measurements of the as-grown $\{111\}$ facet at outer (a) and central (b) part of the melt-solid interface.

Figs. 3 and 4 show AFM pictures taken on the different growth facets. The measurements were performed at melt droplet free regions. Step flow can be observed for the three surfaces with different step heights. On the one hand, step bunching is indicated in Fig. 3b for the $\langle 110\rangle$ pulling direction with step heights between 5 and 31 unit cell distances $a$ and average step distances of $136 \pm 40 \mathrm{~nm}$. On the other hand, step heights between $1-2 a$ and step distances of $65 \pm 12 \mathrm{~nm}$ were measured at the $\{100\}$ facet in case of the pure step flow (Fig. 3a). Furthermore, we observed step meandering instabilities at $\{111\}$ surfaces, which can be explained by the BalesZangwill mechanism [2]. Figs. 4] shows steps at the $\{111\}$ surface with step heights between 44 and $418 a$ and step distances of $1115 \pm 322 \mathrm{~nm}$. The observed differences of the surface morphologies are attributed to the difference of the surface energies which increase in the order $\{100\},\{110\},\{111\}$ [20]. Investigations of the dislocation densities of the grown crystals have shown, that the dislocation density is similar for crystals which were pulled in $\langle 100\rangle$ and $\langle 110\rangle$ direction (growth condition T1-T3, EPD ca. $\left.(1-2) \times 10^{4} / \mathrm{cm}^{2}\right)$. In contrast to that, a higher dislocation density $\left(8 \times 10^{4} / \mathrm{cm}^{2}\right)$ was measured for the crystal which was pulled in $\langle 111\rangle$ direction (T4). These results indicate that the $\langle 110\rangle$ and $\langle 100\rangle$ pulling directions are more favourable due to stable step flow growth and lower dislocation densities.

\subsection{Thermal analysis}

$\mathrm{SrTiO}_{3}$ shows one melting peak (Fig. 1), also during repeated DTA runs, which indicates congruent melting. If the measured onset temperature for $\mathrm{SrTiO}_{3}$ is compared to the $\mathrm{Al}_{2} \mathrm{O}_{3}$ standard, a fusion point $T_{\mathrm{f}}=(2054-1922){ }^{\circ} \mathrm{C}+1947^{\circ} \mathrm{C}=$ $(2079 \pm 20)^{\circ} \mathrm{C}$ is obtained. The error is estimated from the fluctuation of results for these and other substances in this temperature range. Even if a DSC is not available for such high $T$, the heat of fusion can be estimated by comparing the peak area with that of the standard. (One can assume that the sensitivity of the sample carrier is almost identical for $\mathrm{SrTiO}_{3}$ and $\mathrm{Al}_{2} \mathrm{O}_{3}$ because their fusion points differ by only $25 \mathrm{~K}$.) One finds $\Delta H_{\mathrm{f}} \approx 683 \mathrm{~J} / \mathrm{g}=125.2 \mathrm{~kJ} / \mathrm{mol}$. Here a larger error of ca. $\pm 20 \%$ must be assumed, derived from the insufficient reproducibility of this determination. At least this value seems not unrealistic: for the structurally similar $\mathrm{CaTiO}_{3}$ the FactSage [24] database gives at its melting point $1960^{\circ} \mathrm{C}$ a $\Delta H_{\mathrm{f}}=106.638 \mathrm{~kJ} / \mathrm{mol}$.

For the $(1-x) \mathrm{SrO}+x \mathrm{TiO}_{2}$ powder mixtures coming from the $\mathrm{SrO}$ rich side, $x=0.4270$ was the last composition not showing any sign of a eutectic peak (uppermost DTA curve in the insert of Fig. 5), and the next composition, $x=0.4533\left(3^{\text {rd }}\right.$ experimental point from the left in Fig. 5), already showed a minor eutectic peak $(A=2.6 \mathrm{~J} / \mathrm{g})$. The largest eutectic peak 


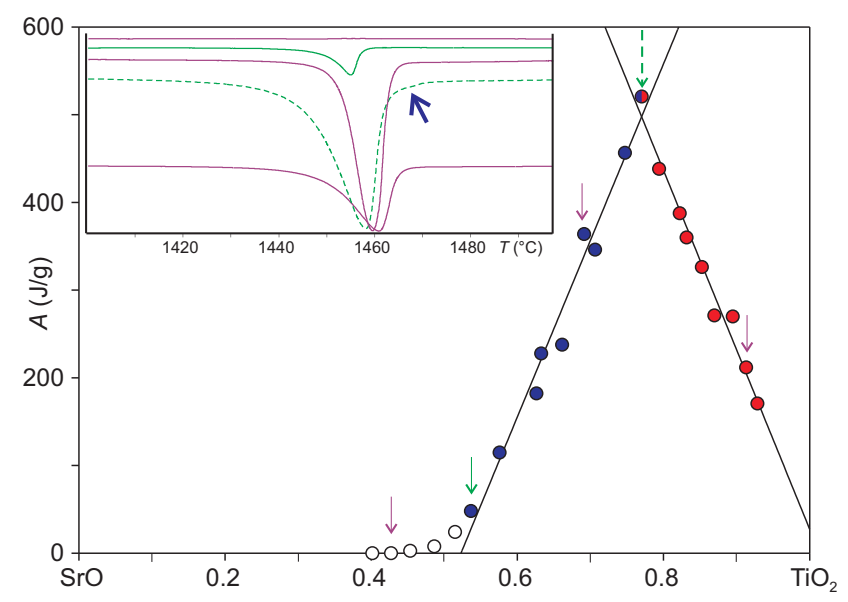

Fig. 5 Tammann plot of the eutectic peak area $A$ vs. $\mathrm{TiO}_{2}$ mole fraction $x$. Full points left or right from $x_{\text {eut }}$ were fitted by linear functions separately. A few DTA curves of the eutectic peaks are shown in the insert; the corresponding points in the plot are marked by an arrow. The dashed DTA curve is for $x=0.7700$, which is almost the intersection of the linear fits at $x_{\text {eut }}=0.7701$.

was found for $x=0.7700(A=520.7 \mathrm{~J} / \mathrm{g})$. The extrapolated onsets of the eutectic peaks vary for all compositions in a small range of $(1449 \pm 3)^{\circ} \mathrm{C}$, which is the eutectic temperature $T_{\text {eut }}$. It is obvious from the lever rule that the peak area $A$ varies linearly with $x$, with a maximum at $x_{\text {eut }}$. Fig. 5 shows such Tammann construction and from the intersection of linear fits $A(x)$ from both sides one obtains $x_{\text {eut }}=0.7701$, which almost coincides with the experimental point and the DTA curve that is marked by dashed lines.

\subsection{Thermodynamic calculations}

With the Schröder-van Laar equation one can calculate a pseudo-binary phase diagram $\mathrm{SrTiO}_{3}-\mathrm{TiO}_{2}$ from the melting point and heat of fusion of both end members. Data for $\mathrm{SrTiO}_{3}$ were estimated by the DTA measurements shown in Fig. 1 and reliable values for $\mathrm{TiO}_{2}\left(T_{\mathrm{f}}=1857^{\circ} \mathrm{C}, \Delta H_{\mathrm{f}}=46024 \mathrm{~J} / \mathrm{mol}\right)$ can be found in FactSage databases [24]. With these data a hypothetical eutectic point at $x=0.8053$ (in scales of $\mathrm{SrO} / \mathrm{TiO}_{2}$ ) and $T=1652^{\circ} \mathrm{C}$ can be calculated if the melt was ideal, which is far way from the measured values $x=0.7701, T_{\text {eut }}=$ $1449^{\circ} \mathrm{C}$. To reach such low $T_{\text {eut }}$ for an ideal melt, $\Delta H_{\mathrm{f}}$ of $\mathrm{SrTiO}_{3}$ would have to be only $\frac{1}{3}$ of its measured value, which can be ruled out. Instead one can conclude that the melt is stabilized by a very large negative excess enthalpy, probably resulting from the strong chemical interaction between the Lewis base $\mathrm{SrO}$ and the Lewis acid $\mathrm{TiO}_{2}$.

The excess Gibbs energy of the melt was expressed by

$$
\sum_{a, b} G_{\mathrm{ex}}=y^{b} x^{a}(A+B T)
$$

Table 2 Assessed parameters for the description of melts from $0.5 \leq x \leq 1.0$ by 1

\begin{tabular}{rrrr}
\hline$a\left(\mathrm{TiO}_{2}\right)$ & $b(\mathrm{SrO})$ & $A$ & $B$ \\
\hline 1 & 1 & -256452 & 44.6683 \\
1 & 2 & -7038.11 & -19.2816 \\
1 & 4 & -1042.50 & 7.01178 \\
2 & 1 & 301.955 & -16.3740 \\
4 & 1 & 1385.40 & 32.9610 \\
\hline
\end{tabular}

where $y=1-x$ is the molar fraction of SrO. Reasonable fits of the experimental data $\left(T_{\mathrm{f}}\right.$ for $\mathrm{SrTiO}_{3}, T_{\text {eut }}$ and $x_{\text {eut }}$, a few liquidus temperatures for compositions near $x_{\text {eut }}$ ) were obtained only if exponents $a, b$ up to 4 were taken into consideration. The assessment was performed with FactSage [24] for compositions between $\mathrm{SrTiO}_{3}$ and $\mathrm{TiO}_{2}$ only, because only there experimental data were available. Results are given in table 2 Even if not used in the assessment itself, it turned out the heat of fusion for $\mathrm{SrTiO}_{3}$ that can be calculated from the difference of the enthalpy of the $1: 1$ composition directly below and above $T_{\mathrm{f}}(126.24 \mathrm{~kJ} / \mathrm{mol})$ corresponds almost perfectly with the experimental value mentioned above $\left(\Delta H_{\mathrm{f}}=125.2 \mathrm{~kJ} / \mathrm{mol}\right)$. Only Gibbs energy data for the melt were assessed here, and data for solid $\mathrm{SrTiO}_{3}$ were taken from recent accurate galvanic measurements: $\Delta H_{\mathrm{f}}^{0}=$ $-1653.290 \mathrm{~kJ} / \mathrm{mol}, S=109.128 \mathrm{~J} /(\mathrm{mol} \cdot \mathrm{K}), c_{p}=137.09676+$ $0.00323 T-456.7919 t T^{-0.5}-1195220 T^{-2}$ (in $\mathrm{J} /(\mathrm{mol} \cdot \mathrm{K})$ [7].

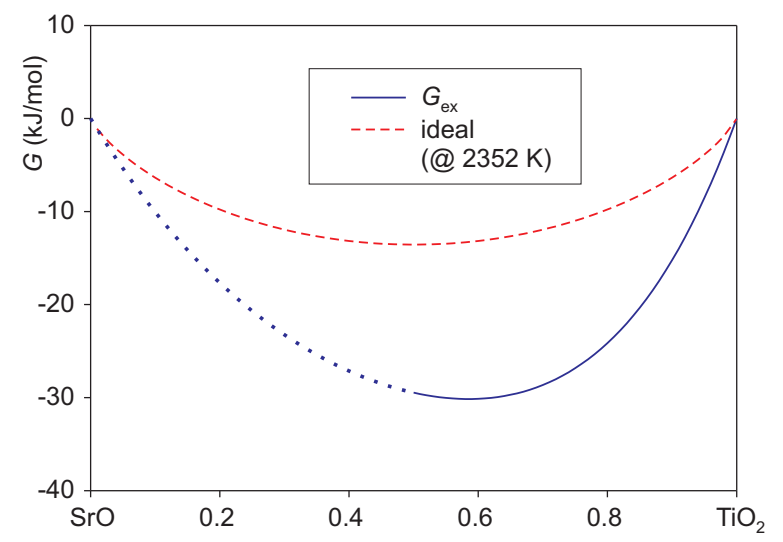

Fig. 6 Gibbs free energy of liquid $\mathrm{SrO} / \mathrm{TiO}_{2}$ mixtures at the melting temperature of $\mathrm{SrTiO}_{3}$. Solid line: real data (equation (1) and table 2, dashed line: ideal mixture for comparison. $G_{\mathrm{ex}}$ data for $x<0.5$ are dotted because no experimental results were available.

Fig. 6 demonstrates that indeed the liquid phase is considerably stabilized, compared with an assumed ideal mixture (dashed curve) at $T_{\mathrm{f}}$ of $\mathrm{SrTiO}_{3}$. The asymmetry of the $G_{\text {ex }}(x)$ curve is responsible for the position of the eutectic point near $x=0.77$ that would otherwise, for a symmetric thermodynamic potential, be shifted to larger $x>0.8$. 


\section{Discussion and conclusions}

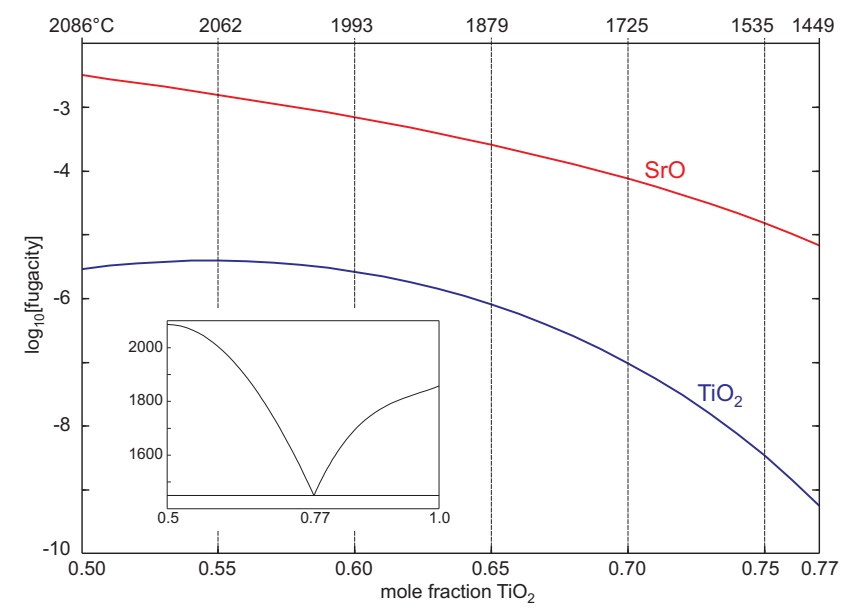

Fig. 7 Fugacity of the main species $\mathrm{SrO}(\mathrm{g})$ and $\mathrm{TiO}_{2}(\mathrm{~g})$ over a $(1-x) \mathrm{SrO}+x \mathrm{TiO}_{2}$ melt for compositions ranging from $\mathrm{SrTiO}_{3}$ $(x=0.5)$ to the $\mathrm{SrTiO}_{3} / \mathrm{TiO}_{2}$ eutectic $(x=0.77)$ at the corresponding liquidus temperatures $T_{\text {liq }}(x)$ which are given as labels on the upper abscissa. The insert shows the phase diagram between $\mathrm{SrTiO}_{3}$ and $\mathrm{TiO}_{2}$.

With the assessed thermodynamic data, equilibria between solids $\left(\mathrm{SrTiO}_{3}, \mathrm{TiO}_{2}\right)$, liquids $\left(\mathrm{SrO}-\mathrm{TiO}_{2}\right.$ melt with $G_{\text {ex }}$ described by (1)), and gas phase ( $\left.\mathrm{SrO}(\mathrm{g}), \mathrm{TiO}_{2}(\mathrm{~g})\right)$ can be calculated, and the results are summarized in Fig.7 It turns out that $\mathrm{SrO}$ has the highest vapour pressure, expressed by its fugacity $f . p_{\mathrm{SrO}}$ is $\gtrsim 3 \mathrm{mbar}$ for pure $\mathrm{SrTiO}_{3}$ at its melting point. Such high fugacity can lead to strontium loss of the melt, which could be accounted for by a slight $\mathrm{SrO}$ excess in the feedstock. Then, however, excess $\mathrm{SrO}$ might be dissolved in the solid e.g. under the formation of Ruddlesden-Popper (RP) phases impeding crystal quality [22, 18]. Measurements with polycrystalline $\mathrm{SrO}\left(\mathrm{SrTiO}_{3}\right)_{n}$ up to $1000 \mathrm{~K}$ showed that the thermal conductivity $\kappa$ is maximum for the cubic perovskite $\mathrm{SrTiO}_{3}$ $(n=\infty)$ and significant lower for RP phases $n=1\left(\mathrm{Sr}_{2} \mathrm{TiO}_{4}\right)$ and $n=2\left(\mathrm{Sr}_{3} \mathrm{Ti}_{2} \mathrm{O}_{7}\right)$ [23]. Oh et al. [13] pointed out that phonons with wavelength in the order of $1 \mathrm{~nm}$ dominate heat transport. $\mathrm{Sr}_{2} \mathrm{TiO}_{4}$ has perpendicular to the $\mathrm{SrO}$ interlayers a lattice parameter $c=1.259 \mathrm{~nm}$ (cf. Fig. 3 top in Ref. [10]) and one can assume that phonon scattering at the $\mathrm{SrO}$ interlayers is responsible for the drop of $\kappa$. For crystal growth from the melt, too low $\kappa$ leads to insufficient heat flux through the crystal, and thus to unstable growth.

By using the TSSG method and $\mathrm{TiO}_{2}$ rich melts, cylindrical $\mathrm{SrTiO}_{3}$ single crystals were grown. In this study a starting composition $x_{0}=0.75$ was used, which is close to $x_{\text {eut }}=0.77$. The proximity of $x_{0}$ to $x_{\text {eut }}=0.77$ restricts crystal yield, but keeps strontium loss by $\mathrm{SrO}$ evaporation negligible $\left(p_{\mathrm{SrO}}=\right.$ $1.5 \times 10^{-5}$ bar at $T_{\text {liq }}=1535^{\circ} \mathrm{C}$, Fig. 7). Under the given experimental conditions ( $\mathrm{Pt}$ crucible in air) $x_{0}$ could be shifted only slightly towards $\mathrm{SrTiO}_{3}$ to increase yield, because then the liquidus temperature quickly exceeds the stability limit of platinum (e.g. $T_{\text {liq }}=1725^{\circ} \mathrm{C}$ with $p_{\mathrm{SrO}}=7.5 \times 10^{-5}$ bar at $x=0.70)$.

In this study, even by using Verneuil-grown seeds, tausonite crystals with higher structural perfection were obtained. Special attention is necessary to avoid the growth of rutile $\left(\mathrm{TiO}_{2}\right)$ on the grown crystal surfaces, and to keep a convex growth interface at the same time. The avoidance of rutile growth and the minimization of frozen melt solution droplets at the growth interfaces reduce the risk of crystal cracking during cooling to room temperature.

AFM investigations have shown that the growth is dominated by the step flow growth mode. Pure step flow, step bunching and step meandering instabilities were observed at growth interface facets $\{100\},\{110\}$ and $\{111\}$, respectively. It can be concluded that $\langle 110\rangle$ and $\langle 100\rangle$ pulling directions from $\mathrm{TiO}_{2}$ rich melts are favourable at low pulling speeds $(0.2 \mathrm{~mm} / \mathrm{h})$, to establish stable step flow growth modes at the growth facets and low dislocation densities in the crystals.

\section{References}

[1] V. I. Aleksandrov, M. A. Vishnyakova, Yu. K. Voron'ko, V. F. Kalabukhova, E. E. Lomonova, V. A. Myzina, and V. V. Osiko. Growth of $\mathrm{SrTiO}_{3}$ single crystals by Czochralski's method from a cold container. Izv. Akad. Nauk SSSR, Neorg. Mater, in russian, 19:104-107, 1983.

[2] G. S. Bales and A. Zangwill. Morphological instability of a terrace edge during step-flow growth. Phys. Rev. B, 41:5500-5508, 1990.

[3] ceramics.org/publications-and-resources/phase-equilibria-diagrams. ACerS-NIST Phase Equilibria Diagrams, CD-ROM Database, Version 3.4, 2012.

[4] D. de Ligny and P. Richet. High-temperature heat capacity and thermal expansion of $\mathrm{SrTiO}_{3}$ and $\mathrm{SrZrO}_{3}$ perovskites. Phys. Rev. B, 53:30133022, 1996

[5] Y. Hotta, T. Susaki, and H. Y. Hwang. Polar discontinuity doping of the $\mathrm{LaVO}_{3} / \mathrm{SrTiO}_{3}$ interface. Phys. Rev. Lett., 99:236805, 2007.

[6] H. Y. Hwang, A. Ohtomo, N. Nakagawa, D. A. Muller, and J. L. Grazul. High-mobility electrons in $\mathrm{SrTiO}_{3}$ heterostructures. Physica E: Lowdimensional Systems and Nanostructures, 22:712-716, 2004.

[7] K. T. Jacob and G. Rajitha. Thermodynamic properties of strontium titanates: $\mathrm{Sr}_{2} \mathrm{TiO}_{4}, \mathrm{Sr}_{3} \mathrm{Ti}_{2} \mathrm{O}_{7}, \mathrm{Sr}_{4} \mathrm{Ti}_{3} \mathrm{O}_{10}$, and $\mathrm{SrTiO}_{3}$. J. Chem. Thermodynamics, 43:51-57, 2011.

[8] A. Kalabukhov, R. Gunnarsson, T. Claeson, and D. Winkler. Electrical transport properties of polar heterointerface between $\mathrm{KTaO}_{3}$ and $\mathrm{SrTiO}_{3}$. arXiv, page 0704.1050, 2007.

[9] R. K. Kirby. Thermal expansion of rutile from 100 to 700 K. J. Res. Nat. Bureau of Standards. Section A: Physics and Chemistry, 71A:363-369, 1967.

[10] Kyu Hyoung Lee, Sung Wng Kim, Hiromichi Ohta, and Kunihito Koumoto. Ruddlesden-popper phases as thermoelectric oxides: Nbdoped $\mathrm{SrO}\left(\mathrm{SrTiO}_{3}\right)_{n}(n=1,2)$. J. Appl. Phys., 100:063717, 2006.

[11] P. Moetakef, T. A. Cain, D. G. Ouellette, J. Y. Zhang, D. O. Klenov, A. Janotti, C .G. Van de Walle, S. Rajan, S. J. Allen, and S. Stemmer. Electrostatic carrier doping of $\mathrm{GdTiO}_{3} / \mathrm{SrTiO}_{3}$ interfaces. Appl. Phys. Lett., 99:232116-232114, 2011. 
[12] P. I. Nabokin, D. Souptel, and A. M. Balbashov. Floating zone growth of high-quality $\mathrm{SrTiO}_{3}$ single crystals. J. Crystal Growth, 250:397-404, 2003.

[13] Dong-Wook Oh, Jayakanth Ravichandran, Chen-Wei Liang, Wolter Siemons, Bharat Jalan, Charles M. Brooks, Mark Huijben, Darrell G. Schlom, Susanne Stemmer, Lane W. Martin, Arun Majumdar, Ramamoorthy Ramesh, and David G. Cahill. Thermal conductivity as a metric for the crystalline quality of $\mathrm{SrTiO}_{3}$ epitaxial layers. Appl. Phys. Lett., 98:221904, 2011.

[14] A. Ohtomo and H. Y. Hwang. A high-mobility electron gas at the $\mathrm{LaAlO}_{3} / \mathrm{SrTiO}_{3}$ heterointerface. Nature, 427:423-426, 2004.

[15] A. Ohtomo, D. Muller, J. Grazul, and H. Hwang. Artificial chargemodulation in atomic-scale perovskite titanate superlattices. Nature, 419:378-380, 2002.

[16] P. Perna, D. Maccariello, M. Radovic, U. S. di Uccio, I. Pallecchi, M. Codda, D. Marre, C. Cantoni, J. Gazquez, M. Varela, S. J. Pennycook, and F. M. Granozio. Conducting interfaces between band insulating oxides: the $\mathrm{LaGaO}_{3} / \mathrm{SrTiO}_{3}$ heterostructure. Appl. Phys. Lett., 97:152111-152113, 2010.

[17] W. H. Rhodes. Etching and chemical polishing of single-crystal $\mathrm{SrTiO}_{3}$. J. Amer. Ceram. Soc. - Discussions and Notes, 49:110-112, 1966.
[18] S. N. Ruddlesden and P. Popper. The compound $\mathrm{Sr}_{3} \mathrm{Ti}_{2} \mathrm{O}_{7}$ and its structure. Acta Cryst., 11:54-55, 1958.

[19] D. Rytz, B. A. Wechsler, C. C. Nelson, and K. W. Kirby. Topseeded solution growth of $\mathrm{BaTiO}_{3}, \mathrm{KNbO}_{3}, \mathrm{SrTiO}_{3}, \mathrm{Bi}_{12} \mathrm{TiO}_{20}$ and $\mathrm{La}_{2-x} \mathrm{Ba}_{x} \mathrm{CuO}_{4}$. J. Crystal Growth, 99:864-868, 1990.

[20] Tomoko Sano, David M. Saylor, and Gregory S. Rohrer. Surface energy anisotropy of $\mathrm{SrTiO}_{3}$ at $1400^{\circ} \mathrm{C}$ in air. J. Am. Ceram. Soc., 86:19331939, 2003

[21] H. J. Scheel, J. G. Bednorz, and P. Dill. Crystal growth of strontium titanate $\mathrm{SrTiO}_{3}$. Ferroelectrics, 13:507-509, 1976

[22] R. J. D. Tilley. An electron microscope study of perovskite-related oxides in the Sr-Ti-O system. J. Solid State Chem, 21:293-301, 1977.

[23] Yi Feng Wang, Kyu Hyoung Lee, Hiromichi Ohta, and Kunihito Koumoto. Fabrication and thermoelectric properties of heavily rareearth metal-doped $\mathrm{SrO}\left(\mathrm{SrTiO}_{3}\right)_{n}(n=1,2)$ ceramics. Ceramics International, 34:849-852, 2008.

[24] www.factsage.com. FactSage 6.4 thermodynamic software and databases, 2013. 